\title{
Impact of primary formaldehyde on air pollution in the Mexico City Metropolitan Area
}

\author{
W. Lei ${ }^{1,2}$, M. Zavala ${ }^{1,2}$, B. de Foy ${ }^{1,3}$, R. Volkamer ${ }^{2,4}$, M. J. Molina ${ }^{2,5}$, and L. T. Molina ${ }^{1,2}$ \\ ${ }^{1}$ Molina Center for Energy and the Environment, CA, USA \\ ${ }^{2}$ Department of Earth, Atmospheric and Planetary Sciences, Massachusetts Institute of Technology, MA, USA \\ ${ }^{3}$ Department of Earth and Atmospheric Sciences, Saint Louis University, MO, USA \\ ${ }^{4}$ Department of Chemistry and Biochemistry, University of Colorado at Boulder, CO, USA \\ ${ }^{5}$ Department of Chemistry and Biochemistry, University of California, San Diego, La Jolla, CA, USA
}

Received: 29 September 2008 - Published in Atmos. Chem. Phys. Discuss.: 18 November 2008

Revised: 31 March 2009 - Accepted: 31 March 2009 - Published: 9 April 2009

\begin{abstract}
Formaldehyde (HCHO) is a radical source that plays an important role in urban atmospheric chemistry and ozone formation. The Mexico City Metropolitan Area (MCMA) is characterized by high anthropogenic emissions of $\mathrm{HCHO}$ (primary HCHO), which together with photochemical production of $\mathrm{HCHO}$ from hydrocarbon oxidation (secondary $\mathrm{HCHO}$ ), lead to high ambient $\mathrm{HCHO}$ levels. The CAMx chemical transport model was employed to evaluate the impact of primary $\mathrm{HCHO}$ on its ambient concentration, on the $\mathrm{RO}_{\mathrm{x}}$ radical budget, and on ozone $\left(\mathrm{O}_{3}\right)$ formation in the MCMA. Important radical sources, including $\mathrm{HCHO}$, $\mathrm{HONO}$, and $\mathrm{O}_{3}$-olefin reactions, were constrained by measurements from routine observations of the local ambient air monitoring network and the MCMA-2003 field campaign. Primary $\mathrm{HCHO}$ was found not only to contribute significantly to the ambient $\mathrm{HCHO}$ concentration, but also to enhance the radical budget and $\mathrm{O}_{3}$ production in the urban atmosphere of the MCMA. Overall in the urban area, total daytime radical production is enhanced by up to $10 \%$ and peak $\mathrm{O}_{3}$ concentration by up to $8 \%$; moreover primary $\mathrm{HCHO}$ tends to make $\mathrm{O}_{3}$ both production rates and ambient concentration peak half an hour earlier. While primary $\mathrm{HCHO}$ contributes predominantly to the ambient $\mathrm{HCHO}$ concentration between nighttime and morning rush hours, significant influence on the radical budget and $\mathrm{O}_{3}$ production starts early in the morning, peaks at mid-morning and is sustained until early afternoon.
\end{abstract}

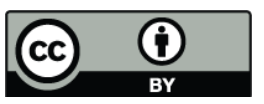

Correspondence to: $\mathrm{W}$. Lei (wflei@mit.edu)

\section{Introduction}

Formaldehyde (HCHO) is the most abundant carbonyl compound in both urban areas and the remote troposphere (Lurmann and Main, 1992; Ho et al., 2002; Hellen et al., 2004). It can be directly emitted from incomplete combustion processes (primary $\mathrm{HCHO}$ ), such as combustion engines and biomass burning, or produced by photooxidation of hydrocarbons (secondary HCHO). Small amounts of HCHO can also be emitted directly from vegetation (Kesselmeier et al., 1997). The major loss processes of HCHO are photolysis and reaction with the hydroxyl radical $(\mathrm{OH})$. HCHO serves as an important primary source for the hydroperoxy radical $\left(\mathrm{HO}_{2}\right)$ and contributes to other odd hydrogen radicals $\left(\mathrm{RO}_{\mathrm{x}}=\mathrm{OH}+\mathrm{HO}_{2}+\mathrm{RO}_{2}\right)$ through the radical propagation processes, which leads to ozone $\left(\mathrm{O}_{3}\right)$ production in the presence of nitrogen oxides $\left(\mathrm{NO}_{\mathrm{x}}\right)$. Because of its widespread presence and its role in $\mathrm{O}_{3}$ and radical photochemistry, $\mathrm{HCHO}$ is an essential component for assessing photochemical processes and radical budgets on local, regional and global scales. Unlike most primary volatile organic compounds (VOCs), photolysis of primary HCHO does not consume radicals, which makes primary $\mathrm{HCHO}$ a unique radical source. HCHO is a known carcinogen (Seinfeld and Pandis, 1998; Molina and Molina, 2002; IARC, 2004); exposure to high levels of ambient $\mathrm{HCHO}$ is detrimental to human health and to the ecosystem.

High concentrations of $\mathrm{HCHO}$ have been measured in the Mexico City Metropolitan Area (MCMA) (Molina and Molina, 2002). Grutter et al. (2005) and Volkamer et al. (2005) report that monthly average concentrations range

Published by Copernicus Publications on behalf of the European Geosciences Union. 
from 4-9 ppb with monthly maxima up to $35 \mathrm{ppb}$ in recent years, which are comparable or higher than those in many US urban cities (EPA, 2005). For example, the annual average concentrations of $\mathrm{HCHO}$ were $2.0 \mathrm{ppb}$ in Chicago, $7.2 \mathrm{ppb}$ in Los Angeles, 4.4 ppb in St. Louis, and $7.9 \mathrm{ppb}$ in Houston in 2005. The high ambient level of HCHO in the MCMA is partially attributed to the direct emissions from mobile and industrial sources (Garcia et al. 2006). According to the emission estimates constructed from the official emissions inventory for the year 2002 in the MCMA (CAM, 2004), mobile and industrial sources are responsible for total $\mathrm{HCHO}$ emissions of about 2050 tons/yr in the MCMA, of which mobile emissions account for about $50 \%$. There is evidence that the mobile emission rates of HCHO in the MCMA and the $\mathrm{HCHO} / \mathrm{CO}_{2}$ emission ratio are much higher than in the US urban areas (Kolb et al., 2004; Zavala et al., 2006). This is probably due to the differences in vehicle fleet characteristics (e.g., fleet age and emission control technology) (Zavala et al., 2006) and the reduced combustion efficiency attributed to high altitude ( $2.2 \mathrm{~km}$ a.s.l. in Mexico City). The high emissions of $\mathrm{HCHO}$ lead us to expect that primary HCHO may play an important role not only in ambient HCHO concentrations, but also in the radical and $\mathrm{O}_{3}$ formation chemistry in the MCMA.

Employing a statistical regression analysis, Garcia et al. (2006) estimate the contribution of primary HCHO to the ambient $\mathrm{HCHO}$ concentration and conclude that a significant amount of HCHO observed in the MCMA is associated with primary HCHO. On a 24-h average, the contributions of primary, secondary and unaccounted sources (background) to ambient $\mathrm{HCHO}$ concentrations are 42,37 , and $21 \%$, respectively, with the primary $\mathrm{HCHO}$ dominating at night and during early morning hours.

A detailed analysis of radical sources in the MCMA is presented by Volkamer et al. (2007) using a box model featuring the Master Chemical Mechanism constrained by an extensive array of measurements. These authors find that contributions of various radical sources $\left(\mathrm{O}_{3}\right.$ photolysis, $\mathrm{HCHO}$ photolysis, HONO photolysis, alkene ozonolyis and photolysis of other oxygenated VOCs (OVOC)) are fairly even in the MCMA. Using the HCHO partitioning results of Garcia et al. (2006), Volkamer et al. (2007) estimate that primary $\mathrm{HCHO}$ accounts for about $10 \%$ of the total radical production before 10:00 a.m., and contributes significantly to photochemical oxidants in mid-morning.

In this study, we employ the 3-D chemical transport model, the Comprehensive Air Quality Model with extensions (CAMx) (ENVIRON 2006), to investigate the impact of primary $\mathrm{HCHO}$ on the photochemistry in the MCMA, with important radical precursors and/or sources constrained by measurements from a local ambient air monitoring network and the MCMA-2003 campaign (Molina et al., 2007). The objective is to examine the influence of primary $\mathrm{HCHO}$ on the odd hydrogen radical budget and $\mathrm{O}_{3}$ formation in the MCMA's atmosphere.

\section{Methodology}

\subsection{Model and input}

CAMx v4.40 with the SAPRC-99 gas phase chemical mechanism (Carter, 2000) was employed in this study. The model configuration and model domain are described in detail in Lei et al. (2007). Briefly, the model domain covers $52 \times 52$ grids with a grid resolution of $3 \mathrm{~km}$ centered in Mexico City; there are 15 vertical layers extending from the surface to about $5 \mathrm{~km}$ a.g.l with the bottom model layer interface of about 64 ma.g.l.

The model was driven by hourly meteorological output fields from the Pennsylvania State University/National Center for Atmospheric Research Mesoscale Model System (MM5, Grell et al., 1995), as described in de Foy et al. (2006). Gaseous emissions were estimated in two steps. First, spatially and temporally resolved and chemically speciated emission fields were constructed based on the official emissions inventory for the year 2002 in the MCMA (CAM, 2004) using the procedures and an updated database described in Lei et al. (2007); these emission fields are referred to as the initial emission estimates henceforth. Second, the initial emission estimates were then adjusted based on observations from the Mexico City Ambient Air Monitoring Network (RAMA) (SIMAT, 2003) and the MCMA-2003 field measurements (Lei et al., 2007). Model runs with varying emissions were carried out and simulated morning rush hour (06:00-09:00 a.m.) speciated VOC (as well as total odd nitrogen $\left(\mathrm{NO}_{\mathrm{y}}\right)$ and $\left.\mathrm{CO}\right)$ concentrations were compared with measurements until a good agreement was reached. Initial chemical concentrations and other boundary conditions were similar to those used in West et al. (2004) and were examined and adjusted using measurements taken at the boundary sites. Photolysis frequencies for clear sky under typical aerosol loading in the MCMA were precomputed using the TUV model (Madronich and Flocke, 1998) and were corrected for the effects of clouds using the algorithm of Chang et al. (1987). Details of the emission estimation and adjustments, as well as other model inputs, are described in Lei et al. (2007).

The simulation episode selected was 13-15 April 2003, for which Lei et al. (2007) has characterized MCMA ozone formation and its response to emission reduction. The base case (with primary $\mathrm{HCHO}$ ) was similar to the reference case in Lei et al. (2007) except a new version of CAMx (v4.40 vs. v4.03) was used and the CMAQ scheme (Byun, 1999) was used to reconstruct the vertical diffusivity fields $\left(\mathrm{k}_{v}\right)$. Because of the changes to the vertical diffusion algorithm in the new version (Greg Yarwood, personal communication, 2007) and because CMAQ scheme overestimates $\mathrm{k}_{v}$ values (de Foy et al., 2007), the vertical diffusivity inputs were adjusted. By comparing $\mathrm{k}_{v}$ values with the results of the O'Brien scheme (1970) used in Lei et al. (2007) and by comparing concentrations of observed primary pollutants 
(mainly $\mathrm{CO}, \mathrm{NO}_{\mathrm{y}}$ ), a day-to-day varying scaling factor of $0.2-0.3$ was applied uniformly (spatially) to the original $\mathrm{k}_{v}$ values.

The photochemical impact of primary $\mathrm{HCHO}$ is identified by turning on and off the $\mathrm{HCHO}$ emissions. As such, the effects of primary $\mathrm{HCHO}$ in $\mathrm{HCHO}$ concentration and photochemistry include not only the influence of the directly emitted HCHO (direct effect), but also the influence from the addition of photochemical HCHO produced through the enhanced photooxidation of hydrocarbons due to the addition of the primary $\mathrm{HCHO}$ (indirect effect). It should be noted that the effect (or impact, contribution, etc.) of primary and secondary $\mathrm{HCHO}$ defined here is different from those reported in Garcia et al. (2006) and Volkamer et al. (2007); we have included the indirect effect in the primary term, whereas the other articles include it in the secondary term.

\subsection{Measurements and model constraints}

One aspect of the complexity in urban photochemistry is the presence of various important radical sources in the urban atmosphere, which include $\mathrm{O}_{3}, \mathrm{O}_{3}$ precursors such as VOCs and $\mathrm{NO}_{\mathrm{x}}$, heterogeneous sources of $\mathrm{HONO}$, and alkene- $\mathrm{O}_{3}$ reactions in the case of the MCMA(Volkamer et al., 2007). A critical aspect for successfully quantifying the impact of primary $\mathrm{HCHO}$ depends on whether these radical sources in the urban areas, in addition to primary $\mathrm{HCHO}$, are accurately captured in the simulation.

The emissions of $\mathrm{CO}, \mathrm{NO}_{\mathrm{x}}$, and speciated VOCs used in the model were constrained by concurrent measurements, as described in Lei et al. (2007). Briefly, simulated CO, $\mathrm{NO}_{\mathrm{x}}$ and $\mathrm{O}_{3}$ were compared with RAMA observations; concentrations of alkanes and alkenes were compared with measurements obtained from canister sampling analyzed by Gas Chromatography/Flame Ionization Detection (GC/FID) at various sites during the MCMA-2003 campaign (Velasco et al., 2007); emissions of aromatics and formaldehyde were evaluated and adjusted by comparing with long-path Differential Optical Absorption Spectroscopy (DOAS) measurements at the campaign supersite CENICA (Volkamer et al., 2005). The DOAS data also included HONO concentrations. Olefin measurements using a Fast Isoprene Sensor (FIS) calibrated with a propylene standard at CENICA (Velasco et al., 2007) were also used in this study.

By comparing the simulated and the measured concentrations of $\mathrm{HCHO}$ and considering findings from previous studies on the mobile emission rate of $\mathrm{HCHO}$ in Mexico City (Kolb et al., 2004; Zavala et al., 2006), a factor of 7 was needed to scale the initial emission estimates of HCHO (from 2050 tons/yr to 13920 tons/yr) in the MCMA in order to reproduce the measured HCHO concentrations. The factor of 7 is consistent with the findings from previous studies on the mobile emission rate of HCHO in the MCMA; both Kolb et al. (2004) and Zavala et al. (2006) show that on average the $\mathrm{HCHO} / \mathrm{CO}_{2}$ emission ratio in traffic exhaust plumes is a fac-

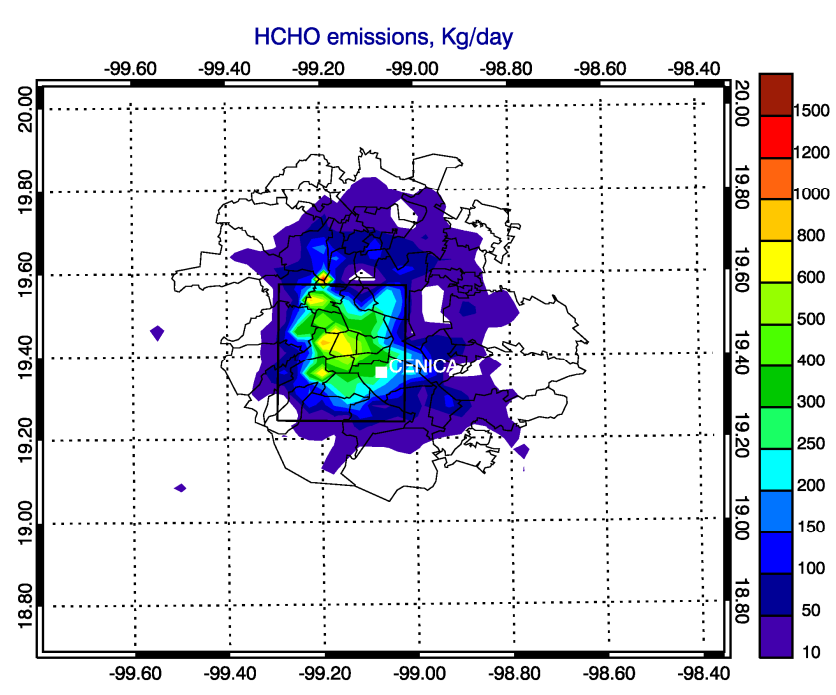

Fig. 1. Spatial distribution of HCHO emissions in the CAMx model domain. The daily emissions have been adjusted from $5615 \mathrm{~kg} /$ day (estimated in the $2002 \mathrm{EI}$ ) to $38140 \mathrm{~kg} /$ day used in this study. The inner black rectangle designates the "urban region" used in the text. Also shown in the figure is the MCMA-2003 campaign supersite CENICA (white square).

tor of 7 higher in the MCMA than in the greater Boston area $\left(2 \times 10^{-4}\right.$ vs. $\left.3 \times 10^{-5}\right)$, although the emission ratio varies with traffic. A map showing the spatial distribution of $\mathrm{HCHO}$ emissions is presented in Fig. 1, which also shows the locations of the CENICA supersite and the "urban region" an area of $30 \times 36 \mathrm{~km}^{2}$ encompassing the MCMA urban center and containing most of the RAMA monitoring stations. Figure 2 provides a comparison of simulated (using adjusted HCHO emissions) and observed HCHO concentrations at CENICA. The model well reproduced the magnitudes and diurnal variations of $\mathrm{HCHO}$ concentration using the adjusted $\mathrm{HCHO}$ emissions, except that it overpredicted HCHO concentrations by $40 \%$ during late afternoon and nighttime (from 16:00 p.m. to 05:00 a.m. next day). The overprediction is probably due to underestimated mixing, rather than overestimated emissions, since the model overestimation during this time window also occurred to $\mathrm{CO}$ and $\mathrm{NO}_{\mathrm{y}}$ (Lei et al., 2007), and morning rush hour concentrations of $\mathrm{HCHO}$ were well reproduced. The HCHO detection limit of DOAS (1 ppb) may also contribute to the discrepancy since during this time window $\mathrm{HCHO}$ ambient concentrations were only a few ppbs (Fig. 2a). For the rest of the time, simulated HCHO were in excellent agreement with the measurements. As discussed later, the overprediction will affect the $\mathrm{HCHO}$ partitioning during late afternoon and nighttime, but should have little effect on the photochemistry, because the photochemical influence of primary $\mathrm{HCHO}$ is most significant in the morning and early afternoon.

In the MCMA, $85 \%$ of radical sources are produced from photochemical reactions (Volkamer et al. 2007), and light 
(a)

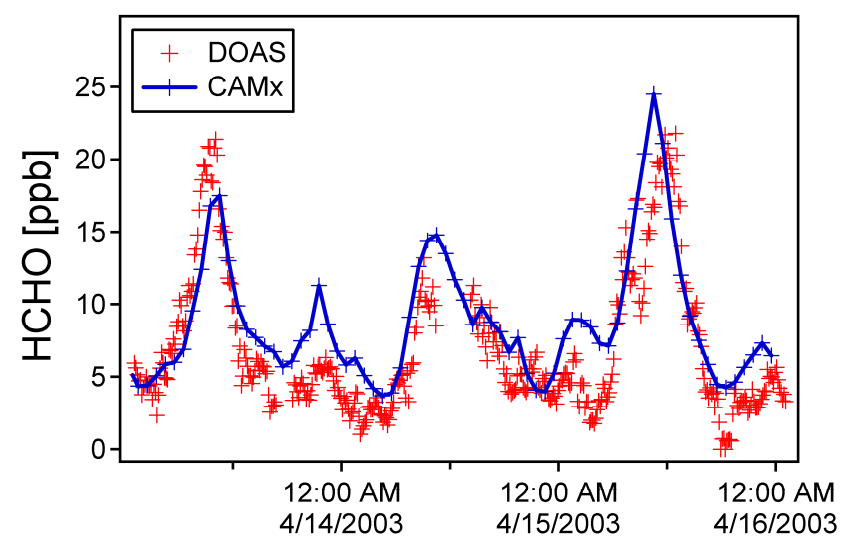

(b)

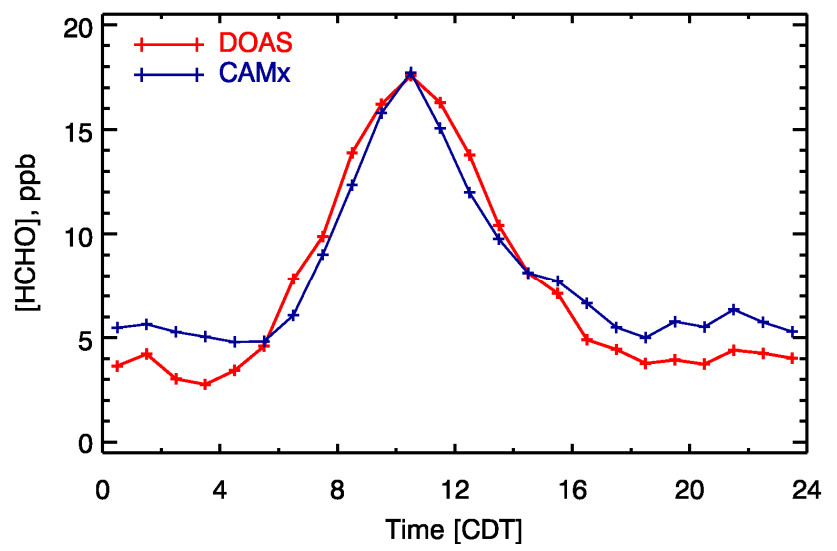

Fig. 2. Comparison of measured and simulated of (a) day-to-day variation and (b) episode-averaged (13-15 April) diurnal variation of surface $\mathrm{HCHO}$ concentrations at CENICA. DOAS measurements are denoted by the red crossed line, while simulated values are denoted by the blue crossed line.

absorbing organic aerosol reduces the amount of sunlight that reaches the ground, lowering radical production from photochemical sources such as $\mathrm{HCHO}, \mathrm{HONO}, \mathrm{O}_{3}$, and OVOC photolysis (Barnard et al. 2008). To account for the effects of aerosol on the radiation using a first-order approximation, the aerosol optical depth at $340 \mathrm{~nm}$ was set to 0.8 for Mexico City in the TUV computation of photolysis frequency, conforming to the concurrent LIDAR aerosol extinction measurements reported during the 2003 campaign (Frey et al., 2004; Simeonov et al., 2004). In addition, a wavelengthindependent value of aerosol single scattering albedo (SSA) in the urban area was set to 0.90. Barnard et al. (2008) report morning hour SSA values as low as 0.78 at $368 \mathrm{~nm}$ in the MCMA and SSA is wavelength dependent. We examined the simulated J-values in the urban area, and they were in good agreement with those measured by spectroradiometry during MCMA-2003 (Volkamer et al., 2005); for example,

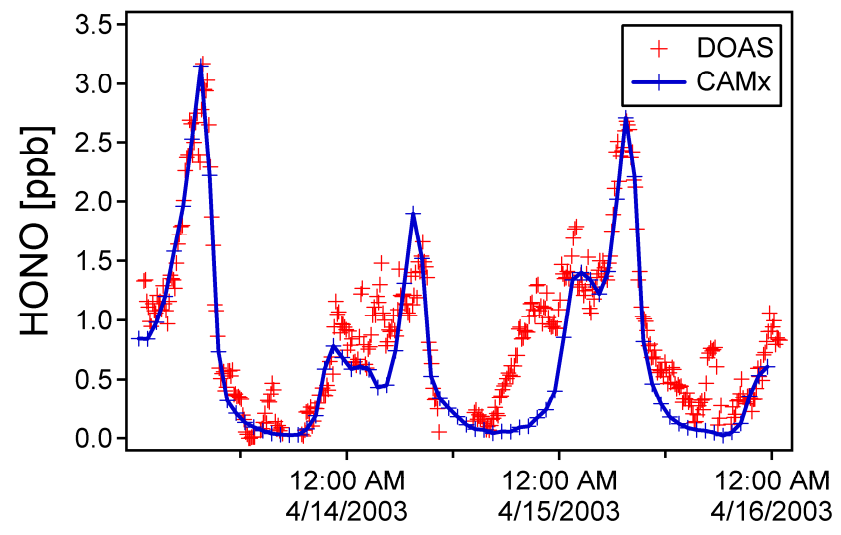

Fig. 3. Comparison of measured and simulated time series of surface HONO concentrations at CENICA. DOAS measurements are denoted by the red crosses, while simulated values are denoted by the blue crossed line.

$\mathrm{JNO}_{2}$ was about $30 \mathrm{~h}^{-1}$ at noon. It should be noted that although the near surface J-values were well simulated using a SSA value of 0.90 combined with other aerosol parameters, the assumption of smaller aerosol absorptivity would lead to an overestimate of J-values aloft, which in turn may lead to an overestimate of radical production.

Heterogeneous chemistry is a major source for nighttime HONO (Platt et al., 1980a; Kleffmann et al., 1998; Finlayson-Pitts et al., 2003; Stutz et al., 2004). However, since the formation mechanism is still not well understood, a direct emission of HONO was artificially included in the model as the surrogate for the heterogeneous source. The magnitude and temporal variation of the estimated HONO emissions were based on the NO emissions and were constrained by the DOAS HONO measurements; i.e., the temporal variation of HONO emissions were adjusted until the simulated HONO agreed with the measurements. A comparison of the simulated and observed HONO concentrations is shown in Fig. 3, which illustrates good agreement between the two.

Volkamer et al. (2007) find that alkene ozonolysis contributes significantly $(\sim 18 \%)$ to the radical production during morning hours in the MCMA. Oxidation of anthropogenic alkenes also plays a major role in daytime $\mathrm{O}_{3}$ production in the MCMA (Tie et al., 2007) and in the US urban areas (Zhang et al., 2004), particularly in early morning where they dominate $\mathrm{O}_{3}$ production. We did not have direct constraints on this radical source. Instead, this source was indirectly constrained by evaluating the simulations of $\mathrm{O}_{3}$ and VOCs. Figure 4 shows the comparison of simulated and observed diurnal variations of surface concentrations of $\mathrm{O}_{3}$ and alkenes at CENICA averaged over the simulation episode. The alkene (OLE) concentration shown in the figure is the propene-equivalent alkene concentration averaged over 14-15 April measured by the FIS. The OLE comparison 


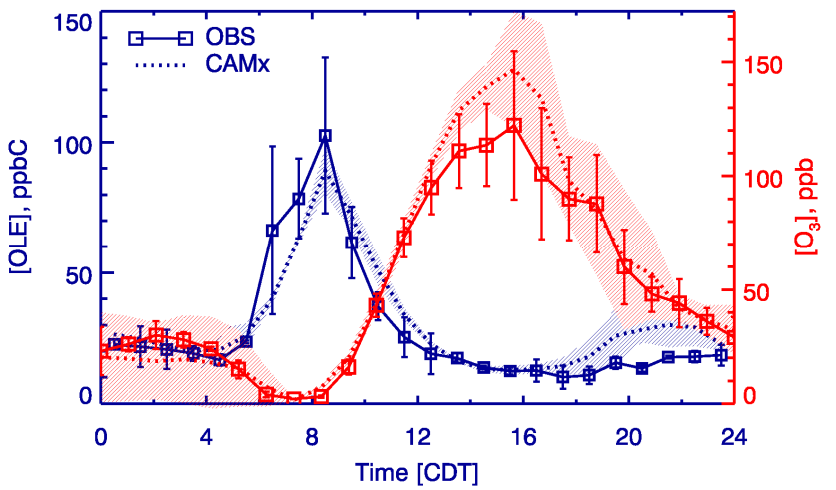

Fig. 4. Comparison of simulated and measured diurnal variations of surface alkene (OLE) in blue and $\mathrm{O}_{3}$ concentrations in red at CENICA. Measurements in solid lines and simulations in dash lines. Error bars represent \pm 1 standard deviations of measurements, and hatched areas represent \pm 1 standard deviations of simulations.

did not include 13 April, which had anomalously high measured VOC concentrations. For the simulated values, concentrations of different olefin model species were weighted based on their FIS response factors and their contributions to the standard VOC mixture used in the SAPRC99 mechanism (Velasco et al., 2007). As shown in the figure, the simulated morning hour concentrations of $\mathrm{O}_{3}$ and OLE agree well with the observations (within $1 \sigma$ level). This suggests that the precursors of this radical source were well constrained, and demonstrates that the $\mathrm{O}_{3}$-OLE reaction is well represented in the model.

$\mathrm{NO}_{3}$-alkene reactions can also be an important source for nighttime peroxy radicals in both marine boundary layer and urban atmosphere (Platt et al., 1980b; Geyer et al., 2003; Lei et al., 2004). Volkamer et al. (2007) report the first direct evidence for the presence of up to $50 \mathrm{ppt} \mathrm{NO} \mathrm{N}_{3}$ inside a megacity (Mexico City), and the relative contribution of this source strongly depends on altitude. Indeed Lei et al. (2004) find that $\mathrm{NO}_{3}$-alkene reactions contribute substantially to nighttime organic radicals in the residual layer in Houston, while their impact is negligible at ground level. In this study there were no constraints for this source.

\section{Results and discussion}

\subsection{HCHO partitioning}

Primary emissions, secondary photochemical formation by VOC oxidation, and background $\mathrm{HCHO}$ all contribute to the simulated concentrations of $\mathrm{HCHO}$. The background $\mathrm{HCHO}$ in the model comes from transport outside the model domain, i.e., from the vertically-varying $\mathrm{HCHO}$ boundary condition which was set to $1.5 \mathrm{ppb}$ at surface in this study. The very low VOC boundary conditions used in this study lead to a negligible contribution to the $\mathrm{HCHO}$ background through
Table 1. Contributions of emissions and secondary formation to ambient $\mathrm{HCHO}$ at CENICA.

\begin{tabular}{lcc}
\hline Time & Primary $(\%)$ & Secondary $(\%)$ \\
\hline 00:00-06:00, 19:00-24:00 & 69 & 24 \\
06:00-09:00(rush h) & 80 & 8 \\
11:00-18:00 & 32 & 67 \\
daily & $5850^{+} 47^{*}$ & $3744^{+}$ \\
\hline
\end{tabular}

+ After correction for the $40 \%$ overprediction of $\mathrm{HCHO}$ concentration at night and early morning.

* Result of Garcia et al. (2006) when the primary HCHO indirect effect is included in the primary term.

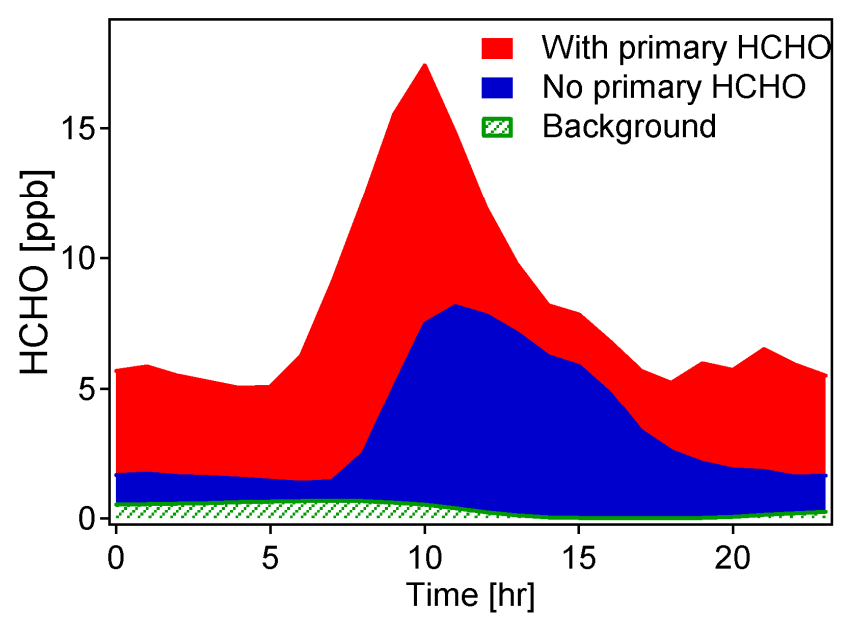

Fig. 5. Partitioning of $\mathrm{HCHO}$ to sources of primary (including the indirect effect), secondary and background at CENICA. The red area denotes the contribution of primary $\mathrm{HCHO}$ to the $\mathrm{HCHO}$ concentration, blue area denotes the contribution of secondary $\mathrm{HCHO}$ when there are no $\mathrm{HCHO}$ emissions, and the hatched green area represents background contributions.

photochemical oxidation. Figure 5 shows the simulated contributions of different sources to HCHO at CENICA. The contribution of primary $\mathrm{HCHO}$ was obtained as the difference between the run with primary emissions (base case) and the other control run without primary emissions. As pointed out earlier, the contribution of primary $\mathrm{HCHO}$ includes not only that of directly emitted $\mathrm{HCHO}$, but also from the additional production of secondary $\mathrm{HCHO}$ through the enhanced photooxidation of hydrocarbons due to the addition of the emitted HCHO (indirect effect). The contribution of the boundary condition on the ambient HCHO concentrations was obtained by calculating the difference in $\mathrm{HCHO}$ concentrations from the control run above with a run where the HCHO boundary conditions were set to 0 . The effect of the $\mathrm{HCHO}$ boundary condition is highest at nighttime but almost vanishes during the late morning to afternoon hours, because of the short chemical lifetime of $\mathrm{HCHO}$ in this period. 
Table 2. Contribution of various radical sources to cumulative radical production in the urban region (unit:ppb). Note all radical terms here are not represented as the $\mathrm{OH}$-equivalent quantities.

\begin{tabular}{ccccccccc}
\hline Time & \multicolumn{3}{c}{$\mathrm{OH}_{\text {new }}$} & \multicolumn{3}{c}{$\mathrm{HO}_{2_{\text {new }}}$} & \multicolumn{2}{c}{$\mathrm{RO}_{2_{\text {new }}}$} \\
\hline & Total & $\mathrm{O}_{3}$ photolysis & $\mathrm{O}_{3} / \mathrm{OLE}$ & HONO photolysis & Total & $\mathrm{HCHO}$ photolysis & Total & Aldehyde photolysis \\
07:00-09:00 & 2.2 & 0.1 & 0.2 & 2.1 & 2.1 & 0.5 & 0.9 & 0.1 \\
09:00-13:00 & 5.7 & 3.8 & 1.5 & 0.4 & 20.9 & 7.5 & 9.0 & 14 \\
13:00-16:00 & 7.7 & 6.7 & 1.0 & 0.0 & 12.8 & 4.8 & 5.3 & 1.0 \\
16:00-20:00 & 2.8 & 1.3 & 1.4 & 0.0 & 4.6 & 1.2 & 3.3 & 0.2 \\
06:00-18:00 & 17.6 & 11.7 & 3.3 & 2.4 & 39.2 & 13.9 & 17.1 & 2.6 \\
Daily & 19.5 & 11.8 & 5.1 & 2.4 & 42.5 & 14.1 & 24.4 & 2.7 \\
\hline
\end{tabular}

Table 1 summarizes the contributions of primary and secondary (not including primary HCHO's indirect contribution) $\mathrm{HCHO}$ as a function of the time of the day. It can be seen from Fig. 5 and Table 1 that primary HCHO contributes significantly to the ambient $\mathrm{HCHO}$ concentration at night and early morning $(\sim 69 \%)$, and culminates at morning traffic rush hours $(\sim 80 \%)$. On the other hand, the contribution of secondary $\mathrm{HCHO}$ to the ambient $\mathrm{HCHO}$ becomes significant during the mid-morning and becomes dominant in the afternoon $(\sim 67 \%)$. On a $24-\mathrm{h}$ basis, the contributions from primary, secondary and background sources are 58, 37 and $5 \%$, respectively. A correction to the $40 \%$ model overprediction (i.e., assuming a perfect agreement) of $\mathrm{HCHO}$ between 04:00 p.m. to 05:00 a.m. (see Sect. 2.2 and Fig. 2b) would modify the corresponding contributions to 50,44, and $6 \%$, respectively.

Garcia et al. (2006) estimate the partitioning of HCHO in the MCMA using a statistical regression analysis, and find that the contributions of the primary, secondary, and background (unaccounted) sources are 42,38 , and $21 \%$, respectively, on a 24-h basis. Note the definitions of primary and secondary sources are different from Garcia et al. (2006), where the indirect effect of emitted $\mathrm{HCHO}$ is included in the secondary term. The model configuration we used did not allow us to quantify the indirect effect, but according to Volkamer et al. (2007), the indirect effect accounts for about $10 \%$ (upper limit) of the primary HCHO. Taking this into consideration, the contributions of primary, secondary and background sources to ambient HCHO in Garcia et al. (2006) would be 47,32 , and $21 \%$ respectively. These corrections bring the results of Garcia et al. (2006) and this study on the primary source contribution to the ambient HCHO concentration to an excellent agreement (within 3\%), even though different methods and time coverage were employed. The definition of the background HCHO in Garcia et al. is significantly different because it represents the source unaccounted for by the tracers of $\mathrm{CO}$ (for emissions) and glyoxal (for secondary). A significant, if not major, portion of the background HCHO in Garcia et al. may consist of the photochemical secondary sources that are not correlated with gly- oxal. Therefore direct comparisons for the secondary and background contributions in the two studies may not be appropriate.

\subsection{Impact on radical budgets}

Photolysis of $\mathrm{HCHO}$ directly produces $\mathrm{HO}_{2}$. $\mathrm{HCHO}$ can also affect $\mathrm{OH}$ and $\mathrm{RO}_{2}$ (organic peroxy radicals) through radical cycling processes. To estimate the overall effects of $\mathrm{HCHO}$ on radical concentrations and radical production rate, the term $\mathrm{OH}$-equivalent (denoted as $\Sigma \mathrm{OH}$, in unit of $\mathrm{ppb} / \mathrm{h}$ ) is used, which takes into account the propagation efficiency of the $\mathrm{HO}_{2} \rightarrow \mathrm{OH}$ and $\mathrm{RO}_{2} \rightarrow \mathrm{OH}$ conversions. Analogous to Sheehy et al. (2008), the conversion efficiencies of $\mathrm{HO}_{2} \rightarrow \mathrm{OH}, \gamma_{\mathrm{HO}_{2}}$, and $\mathrm{RO}_{2} \rightarrow \mathrm{OH}, \gamma_{\mathrm{RO}_{2}}$, are the portion of $\mathrm{HO}_{2}$ and $\mathrm{RO}_{2}$ participating in the radical propagation process that convert to $\mathrm{OH}$ during the propagation, respectively, which are defined as follows:

$$
\begin{aligned}
\gamma_{\mathrm{HO}_{2}} & =\frac{\mathrm{HO}_{2} \rightarrow \mathrm{OH}}{\text { total } \mathrm{HO}_{2} \text { reacted }} \\
\gamma_{\mathrm{RO}_{2}} & =\gamma_{\mathrm{HO}_{2}} \frac{\mathrm{RO}_{2} \rightarrow \mathrm{HO}_{2}}{\text { total } \mathrm{RO}_{2} \text { reacted }}
\end{aligned}
$$

Where $\mathrm{HO}_{2} \rightarrow \mathrm{OH}$ and $\mathrm{RO}_{2} \rightarrow \mathrm{HO}_{2}$ are the propagation rates of $\mathrm{HO}_{2}$ to $\mathrm{OH}$ and $\mathrm{RO}_{2}$ to $\mathrm{HO}_{2}$, respectively. As such,

$\Sigma \mathrm{OH}_{\text {new }}=\gamma_{\mathrm{HO}_{2}} \times \mathrm{HO}_{2_{\text {new }}}+\gamma_{\mathrm{RO}_{2}} \times \mathrm{RO}_{2_{\text {new }}}+\mathrm{OH}_{\text {new }}$

Where $\mathrm{OH}_{\text {new }}, \mathrm{HO}_{2 \text { new }}$ and $\mathrm{RO}_{2_{\text {new }}}$ are the radical initiation rates of $\mathrm{OH}, \mathrm{HO}_{2}$ and $\mathrm{RO}_{2}$ (in unit of $\mathrm{ppb} / \mathrm{h}$ ), respectively, i.e., the rates of radicals produced during the radical initiation process (also defined as new radical production rates). $\mathrm{OH}_{\text {new }}$ is primarily contributed directly by photolysis of $\mathrm{O}_{3}$ and peroxides, alkene ozonolysis, and HONO photolysis. The $\mathrm{HONO}$ photolysis term here is actually the net $\mathrm{OH}$ production from the HONO photolysis minus the $\mathrm{HO}+\mathrm{NO}$ $\longrightarrow \mathrm{HONO}$ reaction. $\mathrm{HO}_{2_{\text {new }}}$ is contributed by photolysis of carbonyls (such as aldehydes and ketones) and alkene- $\mathrm{O}_{3}$ reactions. $\mathrm{RO}_{2_{\text {new }}}$ is contributed by photolysis of carbonyls and alkene- $\mathrm{O}_{3} / \mathrm{NO}_{3}$ reactions; radical production from net 

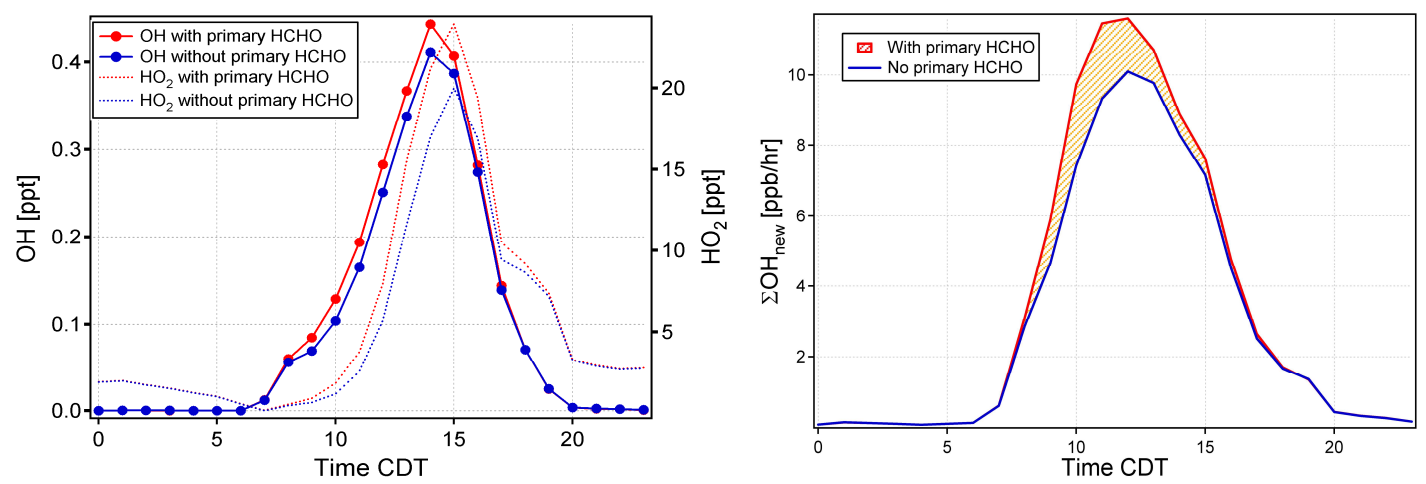

Fig. 6. Effects of primary HCHO on (left) radical concentrations and (right) radical production in the urban region averaged over 13-15 April 2003. In the left panel, solid lines represent the diurnal variations of $\mathrm{OH}$ concentrations, and dashed lines represent the diurnal variations of $\mathrm{HO}_{2}$ concentrations. Inclusions of $\mathrm{HCHO}$ emissions are depicted in red, while exclusions of $\mathrm{HCHO}$ emissions are depicted in blue.

PAN chemical loss (when PAN thermal decomposition minus PAN formation is positive) is also included.

Table 2 shows the contribution of various radical sources to the radical production (initiation) as a function of time during the day (averaged over the episode) in the MCMA urban region. On a 24-h basis the $\mathrm{HO}_{2}$ production is a major radical pool, followed by $\mathrm{RO}_{2}$ and $\mathrm{OH}$ in that order; $\mathrm{HCHO}$ is an important $\mathrm{HO}_{2}$ source, accounting for $33 \%$. It is noted that during 07:00-09:00 a.m. although primary HCHO dominates ambient $\mathrm{HCHO}(\sim 80 \%)$, its contribution to radicals (on the order of $80 \% * 0.5 \mathrm{ppb}=0.4 \mathrm{ppb}$ ) is less important than contributions from $\mathrm{HONO}$ photolysis $\left(\gamma_{\mathrm{HO}_{2}}\right.$ is nearly one at this time) and $\mathrm{O}_{3}$-OLE reactions (the major $\mathrm{HO}_{2}$ production is from $\mathrm{O}_{3}$-OLE reactions). This is consistent with the finding of Volkamer et al. (2007) which suggests that primary $\mathrm{HCHO}$ does not significantly influence the early morning photochemistry.

Figure 6 and Table 3 show the contributions of primary $\mathrm{HCHO}$ to surface radical concentrations and $\mathrm{OH}$-equivalent radical initiation rates in the MCMA urban region. The percentage change for radical concentrations due to primary HCHO is obtained by calculating the enhancement (normalized by the base case) for each hour and then averaging over the hours of interest. The change in radical production is calculated by integrating the radical production rate over the time duration of interest and then computing the enhancement. It is evident that primary $\mathrm{HCHO}$ contributes significantly to the radical budget (starting from 08:00 a.m.), particularly in the morning and early afternoon hours in the MCMA urban area. For example, on the episode-average basis, the contribution of primary $\mathrm{HCHO}$ to $\mathrm{OH}$ concentration increases from $5 \%$ in the early morning to $16 \%$ in the late morning and early afternoon, peaking at about $20 \%$ at 10:00 a.m. It enhances peak $\mathrm{OH}$ concentration by $7 \%$. For $\mathrm{HO}_{2}$, the primary $\mathrm{HCHO}$ contribution increases from $10 \%$ at early morning to $31 \%$ at late morning and early afternoon, peaking at $34 \%$ at 10:00 a.m., and enhances peak concentra-
Table 3. Percentage increases of radical concentrations and initiation rates due to primary $\mathrm{HCHO}$.

\begin{tabular}{ccccc}
\hline Time & $\Delta\left[\mathrm{HO}_{2}\right], \%$ & $\Delta[\mathrm{OH}], \%$ & \multicolumn{2}{c}{$\Delta \Sigma \mathrm{OH}_{\text {new }}, \%$} \\
& & & + & $*$ \\
\hline 07:00-09:00 & 10 & 5 & 6 & 5 \\
09:00-13:00 & 31 & 16 & 17 & 17 \\
13:00-16:00 & 20 & 7 & 8 & 8 \\
16:00-20:00 & 10 & 5 & 6 & 5 \\
06:00-18:00 & 18 & 8 & 12 & 10 \\
Daily & 11 & 5 & 12 & 5 \\
\hline
\end{tabular}

+ Numbers are calculated by integrating the radical production rate over the time duration of interest then computing the enhancement. * Numbers are obtained by calculating the enhancement for each hour then averaging over the hours of interest, same as for the calculation of the enhancement in the radical concentration.

tion by $16 \%$. Note that its contribution to the $\mathrm{HO} 2$ concentration remains important (20\%) till late afternoon.

The contribution to the $\mathrm{OH}$-equivalent primary radical production rate $\left(\Sigma \mathrm{OH}_{\text {new }}\right)$ is similar to that of $\mathrm{OH}$ concentration during daytimes, but the $\Sigma \mathrm{OH}_{\text {new }}$ peaks much earlier. On the 24-h basis, primary $\mathrm{HCHO}$ enhances $\mathrm{OH}, \mathrm{HO}_{2}$ and $\Sigma \mathrm{OH}_{\text {new }}$ by 5,11 and $12 \%$, respectively. The contributions of primary $\mathrm{HCHO}$ to daytime (06:00-18:00 LT) $\mathrm{OH}, \mathrm{HO}_{2}$, and $\Sigma \mathrm{OH}_{\text {new }}$ are 8,18 , and $12 \%$, respectively. If the enhancement for $\Sigma \mathrm{OH}_{\text {new }}$ is calculated the way the radical concentration enhancement is computed, which is used in Volkamer et al. (2007), the average contribution of primary HCHO to daytime $\Sigma \mathrm{OH}_{\text {new }}$ is $10 \%$, as shown in Table 3. Unlike the contribution to ambient $\mathrm{HCHO}$ concentrations, which dominates during the night and early morning but decreases significantly after late morning, important contributions of primary HCHO to radical concentrations and production are evident after 09:00 a.m. and continue into early afternoon. 


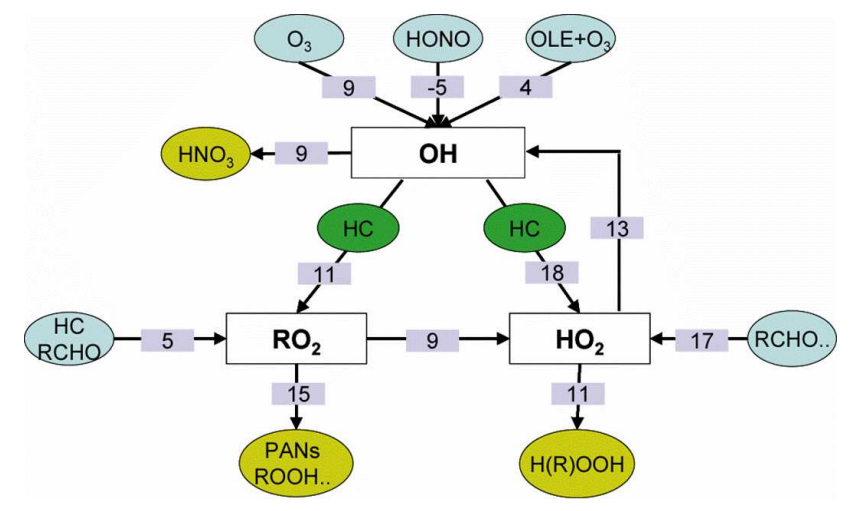

Fig. 7. Effects of primary $\mathrm{HCHO}$ on the radical flows in the urban region. The numbers on each arrow indicate the percentage change of radical chemical flux that follows each pathway accumulated over the entire simulation episode and over the urban region. $\mathrm{RCHO}$ includes HCHO. Radical sources are color-coded by lightblue and radical sinks by olive. $\mathrm{H}(\mathrm{R}) \mathrm{OOH}$ represents $\mathrm{H}_{2} \mathrm{O}_{2}$ and $\mathrm{ROOH}$.

Using a box model with the Master Chemical Mechanism constrained by comprehensive measurements, Volkamer et al. (2007) quantified the radical sources in the MCMA. One of their findings is that primary $\mathrm{HCHO}$ (including the indirect effect) contributes up to $10 \%$ to $\Sigma \mathrm{OH}_{\text {new }}$ in the morning and 7\% for the 06:00-18:00 LT average (9 and 6\% respectively if the indirect effect is excluded) at CENICA. Our results yield about $40 \%$ higher primary $\mathrm{HCHO}$ contributions; part of this discrepancy may be due to the assumption of aerosol's smaller absorptivity used in the TUV calculation, which would lead to an overestimate of UV radiation aloft, resulting in an overestimate of the relative contribution from primary $\mathrm{HCHO}$, even though the total radical production would also be overestimated. Another issue is that in Volkamer et al. (2007) the HCHO source attributed to VOC oxidation was evaluated by setting all but one class of VOC or oxidant of interest to zero, which leads to an upper limit radical production from secondary HCHO. A third issue is that our results are derived from a 3-day simulation average, while Volkamer et al. (2007) use median constraints for the entire one month MCMA-2003 campaign. In addition, the spatial range is different (urban region vs. CENICA). Despite these differences, the agreement is still reasonable. The 06:00-18:00 LT average production rate of $\Sigma \mathrm{OH}_{\text {new }}$ is $6.0 \mathrm{ppb} / \mathrm{h}$, which is in excellent agreement with $6.1 \mathrm{ppb} / \mathrm{h}$ reported by Volkamer et al. (2007).

\subsection{Impact on radical flow}

Radicals are formed from the photolysis of $\mathrm{O}_{3}$, aldehydes, and other species; subsequently they undergo propagation reactions, and eventually are removed from the system by radical- $\mathrm{NO}_{\mathrm{x}}$ reactions (e.g., formation of $\mathrm{HNO}_{3}$, PANs, and other organic nitrates) and radical-radical reactions (which
Table 4. Percentage increases of $\mathrm{O}_{3}$ concentrations due to primary HCHO.

\begin{tabular}{ccc}
\hline Time & $\Delta \mathrm{P}\left(\mathrm{O}_{\mathrm{x}}\right)^{+}, \%$ & $\Delta\left[\mathrm{O}_{3}\right]^{*}, \%$ \\
\hline 07:00-09:00 & 10 & 6 \\
09:00-13:00 & 18 & 17 \\
13:00-16:00 & 8 & 8 \\
16:00-20:00 & 8 & 3 \\
Daily & 13 & 6 \\
Peak $\mathrm{O}_{3}$ & 12 & 8 \\
\hline
\end{tabular}

+ Calculated as integrating over hours first then computing the enhancement.

* Calculated as computing the hourly enhancement first then doing average over the hours.

lead to the formation of peroxides). The addition of primary HCHO to the system modifies these radical initiationpropagation-removal processes (radical flow). By tracking the influences of primary $\mathrm{HCHO}$ on the radical flow, we can identify the roles of primary $\mathrm{HCHO}$ in the radical chemistry.

The effect of primary $\mathrm{HCHO}$ on the radical flow in the MCMA is illustrated in Fig. 7, where the number on each arrow indicate the percentage change of radical chemical flux that follows each pathway accumulated over the entire simulation episode and over the urban region. As primary $\mathrm{HCHO}$ is added, new $\mathrm{OH}$ radicals produced from $\mathrm{O}_{3}$ photolysis and alkene ozonolysis increase by 9 and $4 \%$, respectively, as a result of increases in $\mathrm{O}_{3}$ concentration. In contrast, the radical formation from the net HONO source (HONO photolysis minus $\mathrm{OH}+\mathrm{NO} \longrightarrow \mathrm{HONO}$ ) decreases by $5 \%$. This decrease is due to the larger magnitude of the $\mathrm{OH}+\mathrm{NO} \longrightarrow \mathrm{HONO}$ reaction over the photolysis in the early morning (07:00-09:00 a.m.) when primary HCHO is included, which leads to a marginal increase in HONO concentration (not shown), consistent with the HONO source apportionment during morning hours reported by Volkamer et al. (2007). Initiation rates of $\mathrm{HO}_{2}$ and $\mathrm{RO}_{2}$ are increased by 17 and 5\%, respectively, which are attributed to the increase in $\mathrm{HCHO}$ and other species directly from emissions and indirectly from the additional VOC photooxidation. The interconversions between different radicals increase significantly (9-18\%). The radical removal processes are also enhanced: $9 \%$ for $\mathrm{HNO}_{3}, 15 \%$ for organic nitrates, and $11 \%$ for peroxides. The changes in the interconversion rates are basically equal to the changes in radical removal rates, implying that the catalytic efficiency of radicals in $\mathrm{O}_{3}$ formation remains largely unchanged.

In summary, primary $\mathrm{HCHO}$ significantly enhances radical initiation, propagation and termination. The impact of primary $\mathrm{HCHO}$ on radical budgets described in the previous section is the ultimate consequence of the impact of primary $\mathrm{HCHO}$ on the radical flows. 

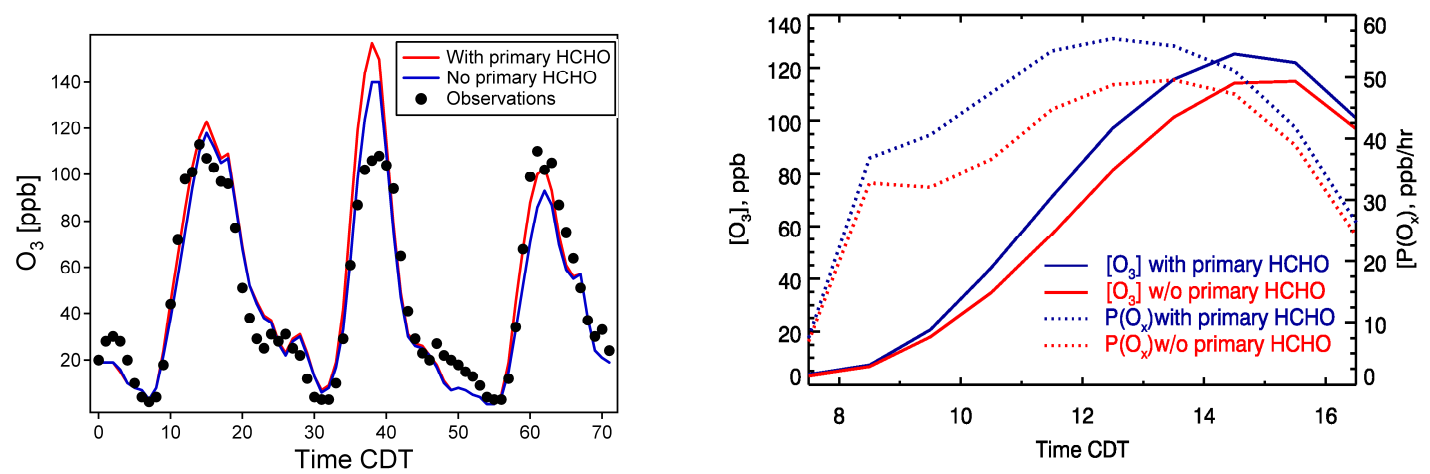

Fig. 8. Effects of primary $\mathrm{HCHO}$ on surface $\mathrm{O}_{3}$ production and concentration in the urban region. RAMA measurements in black dots, simulations with primary $\mathrm{HCHO}$ in red lines, and simulations without primary $\mathrm{HCHO}$ in blue lines. The left panel shows the $\mathrm{O}_{3}$ time series over the whole simulation episode, while the right panel focuses on the morning and afternoon hour $\mathrm{O}_{3}$ production (dotted lines) and concentration (solid lines) averaged over the episode.

\subsection{Impact on $\mathrm{O}_{3}$ formation}

Due to the changes in radical budgets, primary $\mathrm{HCHO}$ is expected to influence $\mathrm{O}_{3}$ photochemical formation in the MCMA. Figure 8 and Table 4 shows the time series of simulated surface $\mathrm{O}_{3}$ concentration and photochemical production rates $\mathrm{P}\left(\mathrm{O}_{\mathrm{x}}\right)\left(\mathrm{O}_{\mathrm{x}}=\mathrm{O}_{3}+\mathrm{NO}_{2}\right)$ averaged over the urban region, with and without primary $\mathrm{HCHO}$ emissions. The enhancement of ambient $\mathrm{O}_{3}$ concentration by primary $\mathrm{HCHO}$ starts to emerge during the morning rush hours with values up to $6 \%$. This increase should be an upper limit since the early morning hour HCHO concentration was overestimated as mentioned earlier. Primary $\mathrm{HCHO}$ increases the surface peak $\mathrm{O}_{3}$ concentration by $4 \%$ to $10 \%$ (corresponding to changes of 4-17 ppb), varying from day to day, but $8 \%$ on average. Moreover, the increase of peak $\mathrm{O}_{3}$ concentration due to the primary $\mathrm{HCHO}$ is more evident and magnified at locations producing high $\mathrm{O}_{3}$ levels (not shown). The significance of the $8 \%$ contribution of primary $\mathrm{HCHO}$ to $\mathrm{O}_{3}$ concentration can be gauged by considering that a $50 \%$ reduction in emissions of both VOC and $\mathrm{NO}_{\mathrm{x}}$ leads to the decrease of urban surface peak $\mathrm{O}_{3}$ concentrations by $19 \%$ (Lei et al., 2007). The most evident impact of primary $\mathrm{HCHO}$ on surface $\mathrm{O}_{3}$ occurs at mid morning and during the early afternoon (09:00-13:00 LT), where primary HCHO leads to an increase of $\mathrm{O}_{3}$ concentration by $17 \%$ on average (over the episode) in the urban region. After 16:00, the contribution of primary $\mathrm{HCHO}$ decreases rapidly. As in the case of radicals, the significant impact of primary $\mathrm{HCHO}$ on $\mathrm{O}_{3}$ continues into the late afternoon. The effect of primary $\mathrm{HCHO}$ on $\mathrm{O}_{3}$ production rates is similar to that of $\mathrm{O}_{3}$ concentration (the higher increase of $\mathrm{P}\left(\mathrm{O}_{\mathrm{x}}\right)$ at photochemically-dark times, when changes in both $\mathrm{O}_{3}$ and $\mathrm{P}\left(\mathrm{O}_{\mathrm{x}}\right)$ are nearly zero,, is mainly due to the difference in the enhancement calculation procedure). Nevertheless the effect of primary HCHO on $\mathrm{P}\left(\mathrm{O}_{\mathrm{x}}\right)$ starts earlier than the effect on $\mathrm{O}_{3}$ concentration (note the difference at 07:00-09:00 a.m.). The rapid increase in $\mathrm{P}\left(\mathrm{O}_{\mathrm{x}}\right)$ from 08:00 to 09:00 a.m. in Fig. 8 is due to the HONO radical source.

Primary $\mathrm{HCHO}$ affects not only the magnitude of $\mathrm{O}_{3}$ concentration and photochemical production rates, but also their timing. As shown in Fig. 8, although there are flat and broad peaks in both $\mathrm{P}\left(\mathrm{O}_{\mathrm{x}}\right)$ and $\mathrm{O}_{3}$ concentration (model output frequency is 1-h), it appears that the primary $\mathrm{HCHO}$ causes $\mathrm{P}\left(\mathrm{O}_{\mathrm{x}}\right)$ to peak half hour earlier $(\sim 12: 30 \mathrm{LT}$ vs. 13:00 LT). It is expected that the timing shift would stand out with a higher output frequency. The peak $\mathrm{P}\left(\mathrm{O}_{\mathrm{x}}\right)$ time shift and greater enhancement of $\mathrm{P}\left(\mathrm{O}_{\mathrm{x}}\right)$ at earlier time stated above lead $\mathrm{O}_{3}$ concentrations to peak about a half hour earlier too ( $\sim$ 14:30 LT vs. 15:00 LT), even though the peak $\mathrm{O}_{3}$ concentration is flat and broad. The timing shift in peak $\mathrm{O}_{3}$ concentration due to primary $\mathrm{HCHO}$ suggests that $\mathrm{O}_{3}$ production is VOC limited in the MCMA source area. Lei et al. (2007, 2008 ) found that a $50 \%$ reduction in $\mathrm{NO}_{\mathrm{x}}$ emissions or a $50 \%$ increase in VOC emissions leads $\mathrm{O}_{3}$ concentration to peak one hour earlier. The timing change together with the influence on peak $\mathrm{O}_{3}$ concentration demonstrates the importance of primary $\mathrm{HCHO}$ in $\mathrm{O}_{3}$ formation in the MCMA.

Finally, it should be noted that our current understanding of the radical production process is incomplete (Volkamer et al., 2007; Sheehy et al., 2008). Radical production fluxes during early morning are uncertain by about a factor of two. Due to the lack of understanding of the underlying physicochemical processes that are causing this mismatch, our discussion of primary HCHO does not attempt to account for this effect. Any additional radical flux from sources that are currently unidentified will reduce the estimates of the contributions of primary $\mathrm{HCHO}$ to the radical budget, as well as ozone formation.

It has been reported that the reaction of electronicallyexcited $\mathrm{NO}_{2}\left(\mathrm{NO}_{2}^{*}\right)$ with water vapor could be a potentially important $\mathrm{OH}$ radical source at high solar zenith angles in the troposphere (Li et al., 2008), and inclusion of this source 
could improve the estimation of radical budget and $\mathrm{O}_{3}$ production in the MCMA (Spencer et al., 2009). However, the significance of this source for Los Angeles $\mathrm{O}_{3}$ production is disputed (Wennberg and Dabdub, 2008). Our preliminary CTM simulation results using the rate constant reported by $\mathrm{Li}$ et al. (2008), which are in preparation for publication, show that the $\mathrm{NO}_{2}^{*}+\mathrm{H}_{2} \mathrm{O}$ radical source is negligible to $\mathrm{O}_{3}$ production in the polluted atmosphere over the MCMA where photochemistry is characterized by complicated radical sources.

\section{Conclusions}

A distinctive feature of the Mexico City metropolitan Area is the high emissions of formaldehyde from anthropogenic sources, in particular from vehicle exhaust. By employing the CAMx chemical transport model for a case run on 1315 April 2003, the impact of primary $\mathrm{HCHO}$ on the ambient $\mathrm{HCHO}$ concentration, radical budgets and $\mathrm{O}_{3}$ formation in the MCMA was examined. Important radical sources, including $\mathrm{HCHO}$, heterogeneous HONO, alkene ozonolysis and other radical precursors, were constrained by measurements from the MCMA-2003 campaign and MCMA's routine ambient air monitoring network.

Primary HCHO contributes significantly to the ambient $\mathrm{HCHO}$ concentration (up to $50 \%$ on daily basis); primary $\mathrm{HCHO}$ dominates ambient $\mathrm{HCHO}$ at night and in the morning (accounting for up to $80 \%$ ), and decreases to $32 \%$ or less in the afternoon.

Primary $\mathrm{HCHO}$ contributes significantly to MCMA's radical budget, including $\mathrm{OH}$ and $\mathrm{HO}_{2}$ concentrations, and the $\mathrm{OH}$-equivalent radical initiation rate $\Sigma \mathrm{OH}_{\text {new }}$, particularly in the morning and early afternoon hours in the urban area. The contribution of primary HCHO to radical formation becomes significant in the early morning, culminates at 09:0011:00 a.m., and continues throughout the early afternoon. It enhances daily $\mathrm{OH}, \mathrm{HO}_{2}$ and total radical initiation rate $\Sigma \mathrm{OH}_{\text {new }}$ by 8,11 and $5 \%$, respectively, while enhancing daytime $\mathrm{OH}, \mathrm{HO}_{2}$, and $\Sigma \mathrm{OH}_{\text {new }}$ by 8,18 , and $12 \%$, respectively. Through its direct effect (radical formation from primary $\mathrm{HCHO}$ itself) and indirect effect (radical formation from enhanced VOC oxidations due to primary $\mathrm{HCHO}$ ), primary $\mathrm{HCHO}$ influences the radical initiation, propagation, and termination, which leads to the increase of $\mathrm{OH}, \mathrm{HO}_{2}$ and $\Sigma \mathrm{OH}_{\text {new }}$.

Primary $\mathrm{HCHO}$ also significantly influences surface $\mathrm{O}_{3}$ formation in the MCMA. Similar to the case for the radical budget, the influence and enhancement of $\mathrm{O}_{3}$ formation by primary HCHO kicks-off in the early morning, peaks at midmorning, and continues through the early afternoon. It not only increases the morning-early afternoon hour surface $\mathrm{O}_{3}$ concentration (up to 19\%), but also increases surface peak $\mathrm{O}_{3}$ concentration ( $8 \%$ on average). Moreover, the increase and enhancement of peak $\mathrm{O}_{3}$ concentration due to the primary $\mathrm{HCHO}$ is more evident and magnified at locations with high $\mathrm{O}_{3}$ levels. Primary $\mathrm{HCHO}$ also tends to make $\mathrm{O}_{3}$ both production rates and concentration peak half an hour earlier.

The conclusions presented in this study are based on one case study, which covers a three-day episode, and the model constraints on important radical precursors, such as $\mathrm{HCHO}, \mathrm{HONO}$, alkene, and $\mathrm{O}_{3}$ heavily rely on measurements at a specific location (CENICA). More studies are needed in order to comprehensively characterize the photochemical impact of primary HCHO with more spatial coverage and broader spatial coverage to improve measurement constraints. In particular it is vital to have an accurate estimate of $\mathrm{HCHO}$ emissions, which requires larger measurement datasets. We plan to further our modeling studies using the much larger and comprehensive datasets from the 2006 MILAGRO Campaign (Molina et al., 2008). In addition, it will be interesting to examine the influence of primary $\mathrm{HCHO}$ on the $\mathrm{O}_{3}-\mathrm{NO}_{\mathrm{x}}-\mathrm{VOC}$ sensitivity chemistry.

Acknowledgements. This work was supported by the Mexican Metropolitan Commission of Environment (CAM) and the US National Science Foundation (ATM-0528227). We would like to thank E. Velasco for assistance in processing the FIS data. We also acknowledge the thoughtful and valuable comments from the two anonymous reviewers and Dr. Kolb, which helped to improve the presentation of this article. CAMx is made publicly available by ENVIRON.

Edited by: C. E. Kolb

\section{References}

Barnard, J. C., Volkamer, R., and Kassianov, E. I.: Estimation of the mass absorption cross section of the organic carbon component of aerosols in the Mexico City Metropolitan Area (MCMA), Atmos. Chem. Phys. Discuss., 8, 10189-10225, 2008,

http://www.atmos-chem-phys-discuss.net/8/10189/2008/.

Byun, D. W.: Dynamically consistent formulations in meteorological and air quality models for multiscale atmospheric studies. Part I: Governing equations in a generalized coordinate system, J. Atmos. Sci., 56, 3789-3807, 1999.

CAM (Comisión Ambiental Metropolitana), 2004: Inventario de Emisiones 2002 de la Zona Metropolitana del Valle de México, México, 2004.

Carter, W. P. L.: Documentation of the SAPRC-99 chemical mechanism for VOC reactivity, final report to California Air Resources Board, Contract 92-329 and 95-308, Calif. Air Res. Board, Sacramento, CA, USA, 2000.

Chang, J. S., Brost, R. A., Isaksen, I. S. A., Madronich, S., Middleton, P., Stockwell, W. R., and Walcek, C. J.: A three-dimensional Eulerian acid deposition model: Physical concepts and formulation, J. Geophys. Res., 81, 421-423, 1987.

de Foy, B., Clappier, A., Molina, L. T., and Molina, M. J.: Distinct wind convergence patterns due to thermal and momentum forcing of the low level jet into the Mexico City basin, Atmos. Chem. Phys., 6, 1249-1265, 2006,

http://www.atmos-chem-phys.net/6/1249/2006/.

de Foy, B., Lei, W., Zavala, M., Volkamer, R., Samuelsson, J., Mellqvist, J., Galle, B., Martínez, A.-P., Grutter, M., Retama, A., and 
Molina, L. T.: Modelling constraints on the emission inventory and on vertical dispersion for $\mathrm{CO}$ and $\mathrm{SO}_{2}$ in the Mexico City Metropolitan Area using Solar FTIR and zenith sky UV spectroscopy, Atmos. Chem. Phys., 7, 781-801, 2007, http://www.atmos-chem-phys.net/7/781/2007/.

ENVIRON: User's guide to the comprehensive air quality model with extensions (CAMx), Version 4.40. ENVIRON Int. Corp., CA, USA, 2006.

Finlayson-Pitts, B. J., Wingen, L. M., Sumner, A. L., Syomin, D., and Ramazan, K. A.: The heterogeneous hydrolysis of $\mathrm{NO}_{2}$ in laboratory systems and in outdoor and indoor atmospheres: An integrated mechanism, Phys. Chem. Chem. Phys., 5, 223-242, 2003

Garcia, A. R., Volkamer, R., Molina, L. T., Molina, M. J., Samuelson, J., Mellqvist, J., Galle, B., Herndon, S. C., and Kolb, C. E.: Separation of emitted and photochemical formaldehyde in Mexico City using a statistical analysis and a new pair of gas-phase tracers, Atmos. Chem. Phys., 6, 4545-4557, 2006, http://www.atmos-chem-phys.net/6/4545/2006/.

Geyer, A., Bächmann, K., Hofzumahaus, A., et al.: Nighttime formation of peroxy and hydroxyl radicals during the BERLIOZ campaign: Observations and modeling studies, J. Geophys. Res., 108(D4), 8249, doi:10.1029/2001JD000656, 2003.

Grutter, M., Flores, E., Andraca-Ayala, G., and Baez, A.: Formaldehyde levels in downtown Mexico City during 2003, Atmos. Environ., 39, 1027-1034, 2005.

Hellen, H., Hakola, H., Reissell, A., and Ruuskanen, T. M: Carbonyl compounds in boreal coniferous forest air in Hyytiala, Southern Finland, Atmos. Chem. Phys., 4, 1771-1780, 2004, http://www.atmos-chem-phys.net/4/1771/2004/.

Ho, K. F., Lee, S. C., Louie, P. K. K., and Zou, S. C.: Seasonal variation of carbonyl compound concentrations in urban area of Hong Kong, Atmos. Environ., 36, 1259-1265, 2002.

International Agency for Research on Cancer: http://www.iarc.fr/en/Media-Centre/ IARC-Press-Releases/Archives-2006-2004/2004/

IARC-classifies-formaldehyde-as-carcinogenic-to-humans, last access: July 2008, 2004.

Kesselmeier, J., Bode, K., Hofmann, U., Müller, H., Schäfer, L., Wolf, A., Ciccioli, P., Brancaleoni, E., Cecinato, A., Frattoni, M., Foster, P., Ferrari, C., Jacob, V., Fugit, J. L., Dutaur, L., Simon, V., and Torres, L.: Emission of short chained organic acids, aldehydes and monoterpenes from Quercus Ilex L. and Pinus Pinea L: in relation to physiological activities, carbon budget and emission algorithms, Atmos. Environ., 31, SI, 119-133, 1997.

Kleffmann, J., Becker, K. H., and Wiesen, P.: Heterogeneous $\mathrm{NO}_{2}$ conversion processes on acid surfaces: Possible atmospheric implications, Atmos. Environ., 32, 2721-2729, 1998.

Kolb, C. E., Herndon, S. C., McManus, J. B., Shorter, J. H., Zahniser, M. S., Nelson, D. D., Jayne, J. T., Canagaratna, M. R., and Worsnop, D. R.: Mobile laboratory with rapid response instruments for real-time measurements of urban and regional trace gas and particulate distributions and emission source characteristics, Environ. Sci., Technol., 38, 5694-5703, 2004.

Lei, W., de Foy, B., Zavala, M., Volkamer, R., and Molina, L. T: Characterizing ozone production in the Mexico City Metropolitan Area: a case study using a chemical transport model, Atmos. Chem. Phys., 7, 1347-1366, 2007,

http://www.atmos-chem-phys.net/7/1347/2007/.
Lei, W., Zavala, M., de Foy, B., Volkamer, R., and Molina, L. T.: Characterizing ozone production and response under different meteorological conditions in Mexico City, Atmos. Chem. Phys., 8, 1-11, 2008, http://www.atmos-chem-phys.net/8/1/2008/.

Lei W., Zhang, R., Tie, X., and Hess, P.: Chemical characterization of ozone formation in the Houston-Galveston area: A chemical transport model study, J. Geophys. Res., 109, D12301, doi:10.1029/2003JD004219, 2004.

Li, S. P., Matthews, J., and Sinha, A.: Atmospheric hydroxyl radical production from electronically excited $\mathrm{NO}_{2}$ and $\mathrm{H}_{2} \mathrm{O}$, Science, 319, 1657-1660, 2008.

Lurmann, F. W. and Main, H. H.: Analysis of the ambient VOC data collected in the Southern California Air Quality Study. Final Report. ARB Contract NO. A832-130, California Air Resources Board, Scaramento, CA, USA, 1992.

Madronich, S. and Flocke, S.: The role of solar radiation in atmospheric chemistry, in Handbook of Environmental Chemistry, edited by: Boule, P., Springer-Verlag, Heidelberg, Germany, 126, 1998.

Molina, L. T. and Molina, M. J. (Eds.): Air Quality in the Mexico Megacity: An Integrated Assessment, Kluwer Academy Publishers, 119-164, 2002.

Molina, L. T., Kolb, C. E., de Foy, B., Lamb, B. K., Bruce, W. H., Jimenez, J. L., Ramos-Villegas, R., Sarmiento, J., ParamoFigueroa, V. H., Cardenas, B., Gutierrez-avedoy, V., and Molina, M. J.: Air quality in North America's most populous cityoverview of MCMA-2003 Campaign, Atmos. Chem. Phys., 7, 2447-2473, 2007, http://www.atmos-chem-phys.net/7/2447/2007/.

Molina, L. T., Madronich, S., Gaffney, J. S., and Singh, H. B.: Overview of MILAGRO/INTEX-B Campaign, IGAC Newsletter, Issue No. 38, 2-15, 2008.

O'Brien, J. J.: A note on the vertical structure of the eddy exchange coefficient in the planetary boundary layer, J. Atmos. Sci., 27, 1214-1215, 1970.

Platt, U., Perner, D., Harris, G. W., Winer, A. M., and Pitts, J. N.: Observations of nitrous-acid in an urban atmosphere by differential optical-absorption, Nature, 285, 312-314, 1980a.

Platt, U., Perner, D., Harris, G. W., Winer, A. M., and Pitts, J. N.: Detection of $\mathrm{NO}_{3}$ in the Polluted Troposphere by Differential Optical Absorption, Geophys. Res. Lett., 7, 89-92, 1980b.

Seinfeld, J. H. and Pandis, S. N.: Atmospheric Chemistry and Physics: From Air Pollution to Climate Change, John Wiley \& Sons, New York, USA, 107-116, 1998.

Sheehy, P. M., Volkamer, R., Molina, L. T., and Molina, M. J.: Oxidative capacity of the Mexico City atmosphere - Part 2: A $\mathrm{RO}_{x}$ radical cycling perspective, Atmos. Chem. Phys. Discuss., 8, 5359-5412, 2008, http://www.atmos-chem-phys-discuss.net/8/5359/2008/.

SIMAT, Sistema de Monitoreo Atmosferico, Ciudad de Mexico, http://www.sma.df.gob.mx/simat/, last access: October 2005, 2003.

Spencer, K. M., McCabe, D. C., Crounse, J. D., Olson, J. R., Crawford, J. H., Weinheimer, A. J., Knapp, D. J., Montzka, D. D., Cantrell, C. A., Anderson, R. S., Mauldin III, R. L., and Wennberg, P. O.: Inferring ozone production in an urban atmosphere using measurements of peroxynitric acid, Atmos. Chem. Phys. Discuss., 9, 2791-2822, 2009,

http://www.atmos-chem-phys-discuss.net/9/2791/2009/. 
Stutz, J., Alicke, B., Ackermann, R., Geyer, A., Wang, S. H., White, A. B., Williams, E. J., Spicer, C. W., and Fast, J. D.: Relative humidity dependence of HONO chemistry in urban areas, J. Geophys. Res., 109, D03307, doi:10.1029/2003JD004135, 2004.

Tie, X., Madronich, S., Li, G., Ying, Z., Zhang, R., Garcia, A., LeeTaylor, J., and Liu, Y.: Characterization of chemical oxidants in Mexico City: A regional chemical dynamical model (WRFChem) study, Atmos. Environ., 41, 1989-2008, 2007.

US Environmental Protection Agency (US EPA): AirData, http: //www.epa.gov/air/data/geosel.html, last access: April 2009, 2005.

Velasco, E., Lamb, B., Westberg, H., Allwine, E., Sosa, G., Arriaga, J. L., Jonson, T., Alexander, M., Prazeller, P., Knighton, B., Rogers, T. M., Grutter, M., Herndon, S. C., Kolb, C. E., Zavala, M., de Foy, B., Molina, L. T., and Molina, M. J.: Distribution, magnitudes, reactivities, ratios and diurnal patterns of volatile organic compounds in the Valley of Mexico during the MCMA 2002 \& 2003 field campaigns, Atmos. Chem. Phys., 7, 329-353, 2007, http://www.atmos-chem-phys.net/7/329/2007/.

Volkamer, R., Molina, L. T., Molina, M. J., Shirley, T., and Brune, W. H.: DOAS measurement of glyoxal as an indicator for fast VOC chemistry in urban air, Geophys. Res. Lett., 32, L08806, doi:10.1029/2005GL022616, 2005
Volkamer, R., Sheehy, P. M., Molina, L. T., and Molina, M. J.: Oxidative capacity of the Mexico City atmosphere Part 1: A radical source perspective, Atmos. Chem. Phys. Discuss., 7, 5365-5412, 2007, http://www.atmos-chem-physdiscuss.net/7/5365/2007/.

Wennberg, P. O. and Dabdub, D.: Atmospheric chemistry - Rethinking ozone production, Science, 319, 1624-1625, 2008.

Zavala, M., Slott, R., S, Dunlea, E. J., Marr, L., Molina, L. T., Molina, M. J., Herndon, S. C., Shorter, J. H., Zahniser, M., Kolb, C. E., Knighton, B., and Rogers, T: Characterization of on-road vehicle emissions in the Mexico City Metropolitan Area using a mobile laboratory in chase and fleet average measurement modes during the MCMA-2003 field campaign, Atmos. Chem. Phys., 6, 5129-5142, 2006, http://www.atmoschem-phys.net/6/5129/2006/.

Zhang, R., Lei, W., Tie, X., and Hess, P.: Industrial emissions cause extreme urban ozone diurnal variability, Proc. Natl. Acad. Sci., USA, 101, 6346-6350, 2004. 